\title{
Potential Use Scenarios of Hybrid Biological Reactor for Petrochemical Industry Wastewater Treatment
}

\author{
Mohd Elmuntasir Ahmed, Rashed Al-Yaseen, Andrzej Mydlarczyk, and Adel Al-Haddad
}

\begin{abstract}
As petrochemical industrial wastewater contains many recalcitrant compounds, the potential of hybrid biological reactors may present a resource to be tapped, especially in the actual operation of an industrial wastewater treatment facility such as Al-Wafra industrial wastewater treatment plant in Kuwait treating primarily petrochemical industry wastewater.

This paper examines possible scenarios for use of hybrid reactors in existing Al-Wafra industrial wastewater treatment plant to improve its efficiency due to loss of biomass in the activated sludge process caused by extreme conditions of the industrial wastewater it receives and its inhibitors. The main innovation in this study, the hybrid reactor was constructed using a biological carrier of the high surface area Random Packing type and was operated using real wastewater samples from Al-Wafra Industrial wastewater Treatment plant. The modalities of operation included high dissolved oxygen levels $(4.0 \mathrm{mg} / \mathrm{l})$, low dissolved oxygen levels $(2.0 \mathrm{mg} / \mathrm{l})$, and under ANNAMOX conditions.

Results revealed that stable biomass have developed on the support media of the hybrid biological reactor with attached to suspended biomass ratio exceeding $70 \%$ and improved efficiency of the first sequence (hybrid-to-ASP) process for TOC removal of $11-17 \%$ and $19-26 \%$ for the second sequence (ASP-to-hybrid) combination depending on the operating conditions. These results clearly reflect the unfavorable conditions for biodegradation after the primary chemical treatment at Al-Wafra plant.

In addition, the dominant bacterial species were identified as pseudomonas species favor less acidic environments which were achieved after the ASP. In terms of nitrification/denitrification, the process met the ammonia and total nitrogen Kuwait standards for irrigation water of 15 and 35 respectively.
\end{abstract}

Index Terms-Hybrid biological reactors, industrial wastewater, wastewater treatment.

\section{INTRODUCTION}

Petrochemical industries are an important industrial sector in Kuwait and internationally as they use and produce considerable amounts of water and wastewater. Petrochemical wastewater is treated using a variety of technologies, including physical and chemical treatment processes such as electro-coagulation, electrochemical oxidation, dissolved air flotation, adsorption, and many others [1]. However, these technologies are costly, use specialized treatment equipment, use huge amounts of chemicals, and produce excessive amounts of sludge.

Manuscript received March 19, 2019; revised May 25, 2019. This work was supported in part by the Kuwait Foundation for the Advancement of Science (KFAS) and Kuwait Institute for Scientific Research (KISR) for funding the study Project No. WT046C.

The authors are with Kuwait Institute for Scientific Research, Water Research Center, Kuwait (e-mail: miahmed@kisr.edu.kw, rayaseen@kisr.edu.kw, amydlarczyk@kisr.edu.kw, ahadad@kisr.edu.kw).
Biological processes are preferred since they are simple, inexpensive, and environmental friendly in their operation [1].

Biological processes can be one of three types, namely, suspended, attached, or hybrid processes. The suspended growth process utilizes suspended microorganisms to degrade contaminants in the wastewater; the attached growth process utilizes solid media to grow the microorganisms in order to reduce their loss rate, and the hybrid process is a combination of both and can be configured and operated in a variety of ways to maximize efficiency and maintain flexibility.

In many instances integrated film biological reactors or biofilm reactor, intended by design, may actually be operating in a suspended and/or attached biological growth modes and, therefore, these reactors are termed "hybrid" biological reactors. The hybrid reactor process can be used as a normal wastewater treatment process the same way as an activated sludge process (ASP) or an attached growth process. In addition to their many advantages including good performance, simplicity of operation, and ability to absorb shock loads, hybrid biological reactors can be optimized to maximize degradation rates of organics including compounds of emerging concern and, hence, they are promising technology in treating industrial wastewaters [2].

In this paper, the research is focused on improving the performance of the activated sludge process of Al-Wafra industrial wastewater treatment plant in Kuwait. A hybrid biological reactor is proposed for this purpose. A background on Al-Wafra industrial wastewater treatment plant is given next.

Al-Wafra Industrial Wastewater Treatment Plant. Al-Wafra Industrial Wastewater Treatment Plant is the only industrial wastewater treatment in Kuwait. The plant consists of preliminary treatment, chemical treatment and biological treatment at the secondary level. Disinfection by chlorination is then applied to effluent before storage in storage tanks. The plant does not utilize anaerobic processes or advanced treatment processes to further polish its effluent.

Al-Wafra Industrial Wastewater Treatment Plant receives industrial wastewater from various industries via tankers to the maximum daily capacity of $7,500 \mathrm{~m}^{3}$. According to Al-Dhafeeri [3] around 300 tankers daily undergo testing before admitting their wastewater into the plant and in case tests indicate unsuitability some will be rejected. The accepted tankers are responsible for 5,000 m3/d load at which the plant is operating currently. This level of operation is maintained and imposed by the volume of generated sludge [3]. Industrial wastewater treatment in Kuwait has been briefly addressed in previous Kuwait Institute for Scientific Research (KISR) studies, mainly [3]-[5] and it is evident that 
technology development is one of the key solution areas that was not addressed as these studies addressed sampling of few industrial wastewater sources and examining available records despite the incomprehensiveness of these records. Review of Al-Wafra industrial wastewater treatment plant records, for example, records has indicated that all the daily parameters as well as the monthly parameters are in compliance with the ministry of public works (MPW) tripartite guidelines [3] for the plant. However, not all the parameters in the tripartite guidelines are monitored and not on a daily bases. Additionally, the water reuse criteria of both EPA and MEW are met, but many parameters in these standards are not monitored. Of utmost importance are the biochemical oxygen demand (BOD), metals, ammonia and phenols. For industrial wastewater, contaminants of emerging concern are of utmost importance such as phenols, BTEXs, metals and radionuclides to highlight a few. These contaminants are not efficiently degraded using the current treatment scheme at Al-Wafra and are not currently monitored; a factor that hinders sound decision making on suitable reuse options of this plant's effluent and undermines the confidence in the risks associated with it.

Due to the limited capacity of the plant (only 7,500 $\mathrm{m}^{3} / \mathrm{d}$ total) and the challenges to reuse its effluent, there is a need to study the plant performance, identify its operational issues, and identify ways to optimize its performance in order for it to serve its intended purposes. Additionally, the lack of centralized industrial wastewater treatment plants in Kuwait presents an imperative to study this only plant and identify potential improvements in its performance to serve as a guide for future out-scaling or upgrading to support industrial expansion and environmental protection in Kuwait.

Aims of this paper. This research is aimed at assessing the pilot performance of a hybrid biological reactor in treating industrial wastewater. The main reason for this is to improve the performance of existing industrial wastewater treatment plant and assess the possibilities of a stand-alone treatment process for individual industries. It is hypothesized that reasonable integration scenarios will enable achieving better industrial wastewater treatment process. The main objective of this project is to assess the performance of a pilot hybrid biofilm reactor under different scenarios of treatment for industrial and petrochemical wastewater. This objective can further be broken into sub-objectives as follows:

- To assess the performance of a pilot hybrid biological process in treating organic matter and its nutrient removal efficiency from industrial and petrochemical (refinery or other industry) wastewater

- To find the appropriate sequence or integration scenarios of the hybrid biological reactor in the various treatment schemes currently in use in order to recommend integrating the process into existing and future industrial wastewater treatment plants

- To estimate the costs of the hybrid biological treatment process and the costs of integration in treatment plants or direct use in the petrochemical industry.

\section{EXPERIMENTAL METHODS}

The reactors were run using industrial wastewater from Al-Wafra industrial wastewater treatment plant in Kuwait.
The wastewater concentration varied daily and, therefore, daily analysis of parameters was necessary.

The experiments tested four sets of wastewater (raw, primary treated, aerated, and aerated-and-clarified wastewater). The samples were collected from the inlet to the hybrid biological reactor and after the hybrid biological reactor. The monitoring of and biological characterization of the biofilm has been done using a microscope.

The wastewater samples were analyzed at for temperature, $\mathrm{pH}, \mathrm{DO}, \mathrm{TOC}$, and biomass (VSS). Analysis was conducted using standard procedures as outlined in the Standard Methods for Water and Wastewater Examination [6].

The experiments took into consideration the sequence of the hybrid reactor in the treatment scheme, its efficiency, economic costs, and the overall improvement in the industrial wastewater treatment plant performance. The testing of the integration scenarios was conducted in a pilot hybrid biological reactor using real samples from the various stages of treatment at an industrial wastewater treatment plant in Kuwait. The treatment sequences applied are shown in Table I.

TABLE I: EXPERIMENTAL DESIGN, EXPERIMENTAL CONDITIONS, AND NUMBER OF SAMPLES

\begin{tabular}{|c|c|c|c|c|c|c|c|c|}
\hline \multicolumn{9}{|c|}{ Source of wastewater sample } \\
\hline & \multirow{2}{*}{\multicolumn{2}{|c|}{$\begin{array}{c}\text { Primary treated } \\
\text { Effluent } \\
\text { Loading rate }\end{array}$}} & \multirow{2}{*}{\multicolumn{2}{|c|}{$\begin{array}{c}\text { Aerated wastewater } \\
\text { sample }\end{array}$}} & \multirow{2}{*}{\multicolumn{2}{|c|}{$\begin{array}{l}\text { Aerated and } \\
\text { clarified } \\
\text { Loading rate }\end{array}$}} & \multirow{2}{*}{\multicolumn{2}{|c|}{$\begin{array}{c}\begin{array}{c}\text { Raw from } \\
\text { industry }\end{array} \\
\text { Loading rate }\end{array}$}} \\
\hline & & & & & & & & \\
\hline & High & Low & High & Low & High & Low & High & Low \\
\hline $\begin{array}{l}\text { Aerobic } \\
\text { low air } \\
\text { supply }\end{array}$ & $\mathrm{x}$ & $\mathrm{x}$ & $\mathrm{x}$ & $\mathrm{x}$ & $\mathrm{x}$ & $\mathrm{x}$ & $\mathrm{x}$ & $\mathrm{x}$ \\
\hline $\begin{array}{l}\text { Aerobic } \\
\text { low air } \\
\text { supply }\end{array}$ & $\mathrm{x}$ & $\mathrm{x}$ & $\mathrm{x}$ & $\mathrm{x}$ & $\mathrm{x}$ & $\mathrm{x}$ & $\mathrm{x}$ & $\mathrm{x}$ \\
\hline Anaerobic & $\mathrm{x}$ & $\mathrm{x}$ & $\mathrm{x}$ & $\mathrm{x}$ & $\mathrm{x}$ & $\mathrm{x}$ & $\mathrm{x}$ & $\mathrm{x}$ \\
\hline Reference & $\begin{array}{l}\text { Two ex } \\
\text { using } n\end{array}$ & $\begin{array}{l}\text { ments } \\
\text { cipal }\end{array}$ & $\begin{array}{l}\text { esenting } \\
\text { water }\end{array}$ & aerobic & enario a & best ar & robic sc & \\
\hline
\end{tabular}

\section{RESULTS AND DISCUSSION}

\section{A. Priming the Reactor and Biofilm Characterization}

The first step in readying the hybrid reactors was to prime the using industrial wastewater from Al-Wafra industrial wastewater treatment plant aeration tank. The priming period lasted a month after which the biofilm was characterized using microscopic and VSS analysis.

The VSS content of the packing material was estimated to be 725.0 and $327.5 \mathrm{~g} / \mathrm{m}^{3}$ for the aerobic and anerobic conditions respectively. This indicates that, for packing density of $50 \mathrm{~kg} / \mathrm{m}^{3}$ and packing surface area $148 \mathrm{~m}^{2} / \mathrm{m}^{3}$, the corresponding biofilm thickness is 12.2 and $5.5 \mu \mathrm{m}$ for the aerobic and anerobic conditions, respectively. Initial values for biofilm thickness were observed to be in the order of $1 \mu \mathrm{m}$ as reported by Chang et al. [2]. Therefore the obtained values in our reactor were satisfactory. Under these conditions the attached biomass ratio was typically $70 \%$.

The microscopic analysis shows that a good biofilm coverage was obtained as depicted in Fig. 1 and the biofilm uniformity is remarkable as well as shown in Fig. 2. This performance has been reported earlier by Ahmed et al. [7], [8]. 


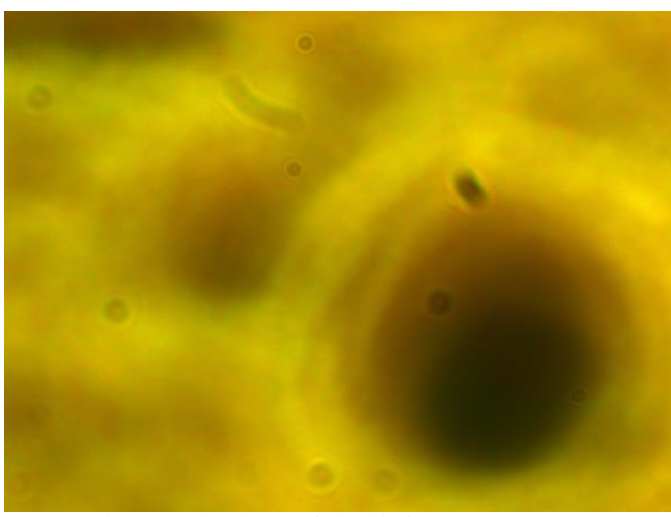

Fig. 1. 10x microscopic photo of the biofilm on the Random Packing support.

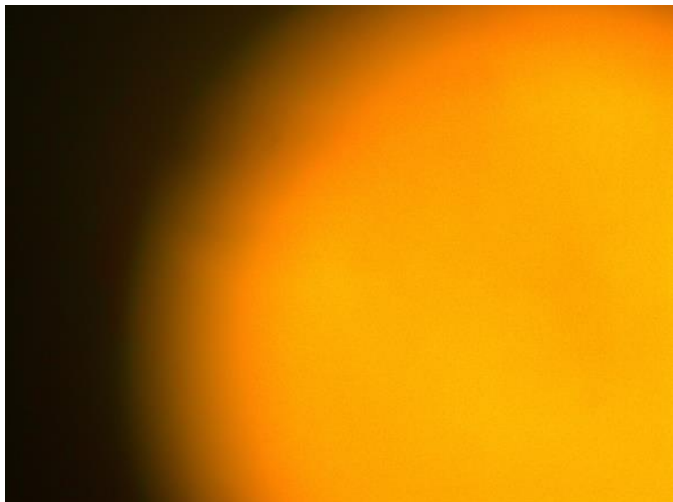

Fig. 2. 3x microscopic photo of the biofilm on the Random Packing support. Bright yellow is the support and orange is the biofilm.

Isolates identified to include mainly Pseudomonas bacteria including eruginosa, putida, mendocina, and aeruginosa. These Pseudomonas isolates usually perform well in degrading oil based organics.

\section{B. Assessment of the Process Performance under Different Scenarios}

As the wastewater composition fluctuates continuously (increasing and decreasing), the performance of the process was not assessed in terms of its effluent to influent concentrations, rather it was assessed using the normalized TOC cumulative removal rates as shown in Fig. 3-6. The experimental conditions for the aerobic conditions are set initially as low air at $2.0 \mathrm{mg} / \mathrm{l}$, high air at $4.0 \mathrm{mg} / \mathrm{l}$, low flow at $240 \mathrm{ml} / \mathrm{min}$, and high flow at $400 \mathrm{ml} / \mathrm{min}$. for the anaerobic conditions no air was supplied and the reactor was covered.

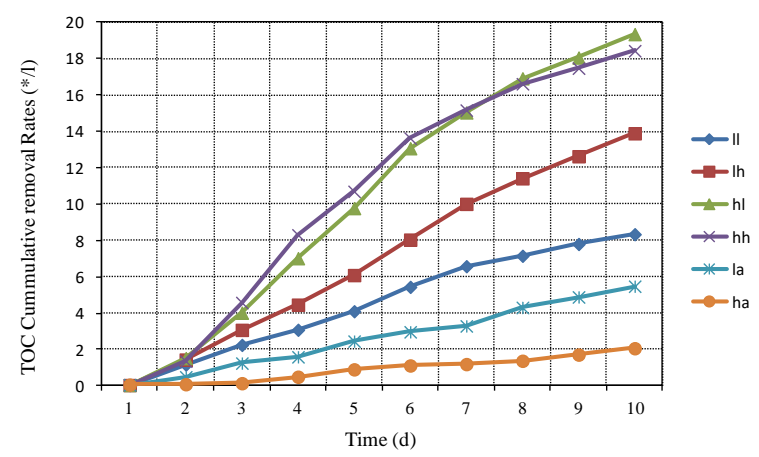

Fig. 3. Normalized TOC cumulative removal rates under different experimental conditions for raw industrial wastewater. 11: low flow low air; lh: low flow high air; hl: high flow low air; hh: high flow high air; la: low flow anaerobic; ha: high flow anaerobic.

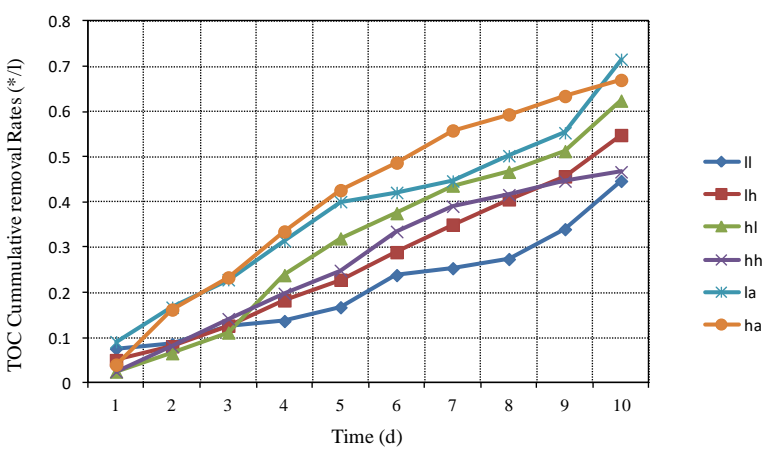

Fig. 4. Normalized TOC Cumulative Removal Rates under Different Experimental Conditions for Primary Treated Industrial Wastewater. 11: low flow low air; lh: low flow high air; hl: high flow low air; hh: high flow high air; la: low flow anaerobic; ha: high flow anaerobic.

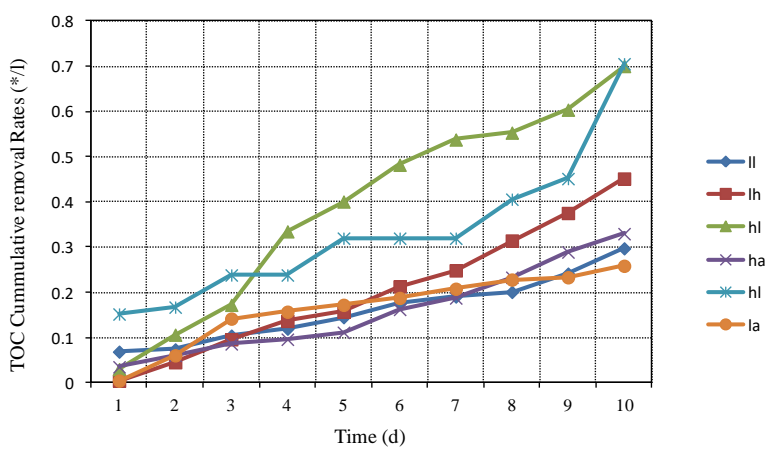

Fig. 5. Normalized TOC cumulative removal rates under different experimental conditions for secondary treated industrial wastewater. 1l: low flow low air; lh: low flow high air; hl: high flow low air; hh: high flow high air; la: low flow anaerobic; ha: high flow anaerobic.

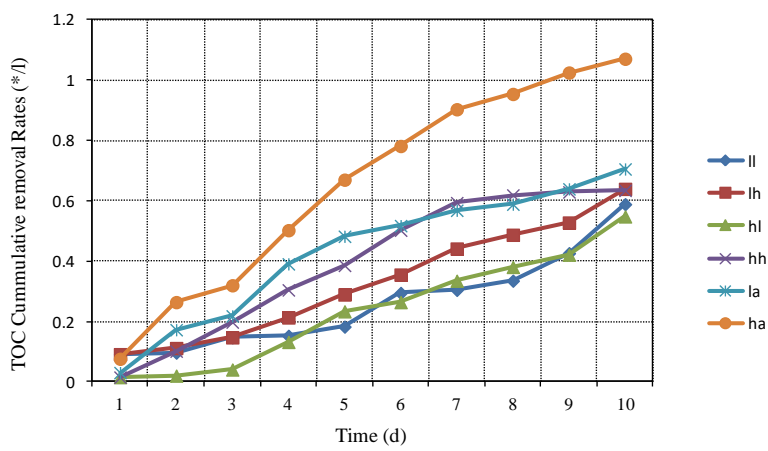

Fig. 6. Normalized TOC cumulative removal rates under different experimental conditions for effluent industrial wastewater. 11: low flow low air; lh: low flow high air; hl: high flow low air; hh: high flow high air; la: low flow anaerobic; ha: high flow anaerobic.

As can be seen from Fig. 4-7 the process could perform well in removing the organics as designed. The best scenario for the raw wastewater is the high flow and low air (Fig. 3), for the primary treated wastewater it is the high flow anaerobic (Fig. 4), for the secondary treated wastewater it is the high flow low air (Fig. 5), and for the effluent wastewater it is the high flow anaerobic (Fig. 6).

A pattern can be seen in the treatment of raw and secondary wastewater as they have the same best scenario (hl) and the primary treated and effluent wastewater have the same scenario (ha). This could be attributed to the low organic content of the effluent wastewater resulting in a low food to microorganisms ratio and to the high salinity/acidity the primary treated wastewater after the chemical treatment 
7]. The primary treated wastewater is also depleted from microorganisms and may cause inhibitory effects on the pilot hybrid reactor.

\section{Identification of Best Operation and Integration Scenarios for Aerobic and Anaerobic Conditions}

From the results of section 2 above, it is clear that the best operating aerobic scenario a is the high flow low air and the best operating anaerobic scenario is the high flow anaerobic as can be seen from Fig. 3-6.

The question for the aerobic scenario is whether to use it for raw wastewater or for secondary treated wastewater or for both. To answer this question we have to recall the use of rotating biological contactors, membrane bioreactors, trickling filters has always been as a supplement or a replacement to the activated sludge process [9]. And therefore we will adopt the tertiary treatment option (that is to use the hybrid biological reactor for secondary treated wastewater) as a best aerobic scenario. In addition, there are some drawbacks for the use of the hybrid biological reactor for raw wastewater including the excessive sludge and the frequent need for cleaning.

For the anaerobic scenario it is a good idea to use it for primary treated or effluent wastewater. However, since we will be using the hybrid reactor as aerobic tertiary treatment it is advisable to use the anaerobic scenario as a supplement or a replacement of the primary treated wastewater. This choice takes into consideration the high removal rates achieved using the anaerobic scenario for effluent as opposed to the primary treated wastewater.

In summary the best anaerobic scenario is (ha) for primary treated wastewater and the best aerobic scenario is the (hl) scenario for secondary treated wastewater.

The results in Fig. 3-6 revealed that improved efficiency of the first best sequence (hybrid-to-ASP anaerobic) process for TOC removal of $11-17 \%$ and $19-26 \%$ for the second sequence (ASP-to-hybrid aerobic) combination depending on the operating conditions. These results clearly reflect the unfavorable conditions for biodegradation after the primary chemical treatment at Al-Wafra plant.

In terms of nitrification/denitrification, the process (ASP-to-hybrid aerobic) met the ammonia and total nitrogen Kuwait standards for irrigation water of 15 and 35, respectively.

\section{COSTING OF THE PROCESS}

Cost estimation is an important consideration for the development and evaluation of wastewater treatment alternatives.

Wastewater treatment costs can be basically divided into two categories: capital costs and operation and maintenance costs. Capital costs are incurred during plant construction, while operation and maintenance costs are those necessary to operate and provide upkeep for the plant following construction. Cost estimates can be made from data reported for similar size plants with similar wastewater and treatment characteristics [10]. In this project, one hybrid pilot reactor cost estimates are listed in Table II for both the pilot capital and operational items.

Wastewater treatment costs can be basically divided into two categories, namely, capital costs and operation and maintenance costs. Capital costs are incurred during plant construction; while operation and maintenance costs are those necessary to operate and provide upkeeping for the plant following construction. Cost estimates can be made from data reported for similar size plants with similar wastewater and treatment characteristics [10]. In this project, one hybrid pilot reactor cost estimates are listed in Table II for both the pilot capital and operational items.

\begin{tabular}{lllrr}
\multicolumn{5}{c}{ TABLE II: PROCESS COMPONENTS AND COSTS } \\
\hline Cost Class & Items & $\begin{array}{l}\text { Number of } \\
\text { units }\end{array}$ & $\begin{array}{r}\text { Price per } \\
\text { unit }(\text { KD })\end{array}$ & $\begin{array}{r}\text { Total } \\
(\text { KD })\end{array}$ \\
\hline Capital & & & & \\
& Hybrid reactor tank & 1 & 150 & 150 \\
& Pumps & 2 & 270 & 540 \\
& Air compressors & 1 & 300 & 300 \\
& Random packing & $1 \mathrm{~m} 3$ & 79 & 79 \\
& Air distribution system & 1 & 15 & 15 \\
& Clarifier tank & 1 & 52 & 52 \\
& Chlorine mixing & 1 & 135 & 135 \\
& & & Total & $\mathbf{1 2 7 1}$ \\
Operational & & & \\
& & 10 days run & 16 & 16 \\
& Sludge Cleaning and maintenance & 10 days run & 5 & 5 \\
& Electrical supply & 10 days run & 16 & 16 \\
& Disinfection chemicals & 10 days run & 75 & 75 \\
& labor & & Total & $\mathbf{1 1 2}$ \\
\hline
\end{tabular}

To scale this system up and to estimate the cost per construction of a cubic meter at a wastewater treatment plant scale, we use equation (1).

$$
C^{p}=C^{l}\left[Q^{p} / Q^{l}\right]^{1 / n}
$$

where, $C^{p}=$ Total cost of full scale; $C^{1}=$ Total annualized cost of laboratory system; $Q^{p}=$ Capacity of pilot system; $Q^{1}=$ Capacity of laboratory system; and $n=$ Parameter representing economies of scale. The $C^{\mathrm{l}}, Q^{p}, Q^{1}$ values $K D$ $1,271,1 \mathrm{~m}^{3}, 0.6 \mathrm{~m}^{3} .1 / \mathrm{n}$ are to be taken as 0.25 . On the basis of capital cost, the cost per cubic meter for a pilot system could be in the range of $K \mathrm{D} 1,445$. This cost is indicative only, and actual pilot costs depend on market and the actual design.

To summarize, in the range of efficiencies achieved, the process economic benefits focused mainly on reduced chemical use, reduced sludge recycling, and improved effluent quality which could be reused in agriculture. For the ASP-hybrid combination it could save up to $45 \%$ of the operating costs of the plant as compared to a preliminary chemical treatment and a larger size ASP process at the plant.

\section{CONCLUSIONS}

Results revealed that stable biomass have developed on the support media of the hybrid biological reactor with attached to suspended biomass ratio exceeding $70 \%$ and improved efficiency of the first sequence (hybrid-to-ASP) process for TOC removal of $11-17 \%$ and $19-26 \%$ for the second sequence (ASP-to-hybrid) combination depending on the operating conditions.

In the range of efficiencies achieved, the process economic benefits focused mainly on reduced chemical use, reduced sludge recycling, and improved effluent quality which could be reused in agriculture. For the ASP-hybrid combination it may save up to $45 \%$ of the operating costs as compared to a larger size ASP process at the plant. 


\section{CONFLICT OF INTEREST}

We believe firmly there is no conflict of interest during the execution of the research project which culminated in this paper.

\section{AUTHOR CONTRIBUTIONS}

Dr. Mohd Elmuntasir Ahmed is the project leader and responsible for the execution of the project and data analysis and reporting tasks of the project (paper writer). Mr. Rashed Al-Yaseen is a team member tasked with operating the reactor according to the operational scenarios planned in the project proposal, and contributed to the modeling, design and analysis of results. Dr. Andrzej Mydlarczyk is the task leader for the experimental task responsible for setting the operational parameters, keeping records of data and conduct quality check and analysis of results. Dr. Adel Al-Haddad is the mobilization task leader responsible for assembly and setting up the pilot reactors and contributed to the write-up of the paper. All authors approve the final version of this paper.

\section{ACKNOWLEDGMENT}

The authors would like to thank Kuwait Foundation for the Advancement of Science (KFAS) and Kuwait Institute for Scientific Research (KISR) for funding the study Project No. WT046C.

\section{REFERENCES}

[1] S. Ishak, A. Malakahmad, and M. H. Isa, "Refinery wastewater treatment: A short review," Journal of Science and Industrial Research, vol. 71, pp. 251-256, 2012.

[2] H. T. Chang, S. J. Parulekar, and M. Ahmed, "A dual-growth kinetic model for biological wastewater reactors," Biotechnology Progress, vol. 21, no. 2, 423-31, 2005.

[3] A. Al-Dhafeeri, "Assessing wafra industrial wastewater treatment plant performance,” Kuwait Institute for Scientific Research, Report No. KISR13300, Kuwait, 2016.

[4] A. M. Shahalam, S. B. Al-Shammari, A. Abusam, and H. Al-Naser, "Present and future wastewater quantities and reuse demand in Kuwait," Kuwait Institute for Scientific Research, Report No. KISR8954R, Kuwait, 2008.
[5] A. M. Shahalam, A. Al-Haddad, A. Abusam, S. Al-Shammari, and H. Al-Naser, "Development of wastewater quality database and assessment of effluent quality for potential reuse in Kuwait," Kuwait Institute for Scientific Research, Report No. KISR9652R, Kuwait, 2010.

[6] APHA, "Standard methods for examination of water and wastewater," American Public Health Association (APHA), Washington, D.C., USA, 2012.

[7] M. E. Ahmed, A. Al-Dhafeeri, and A. Mydlarczyk, Arab J Sci Eng., 2018.

[8] M. E. Ahmed, A. Mydlarcyzk, A. Abusam, "Integrated film process for the treatment of petrochemical wastewater," Kuwait Institute for Scientific Research, Report Bo. KISR13636, 2016.

[9] Metcalf and Eddy, Wastewater Engineering: Treatment and Resource Recovery, NY: McGraw-Hill, 2014.

[10] M. J. Hammer and M. J. Hammer, Water and Wastewater Technology, Fourth Edition, Prentice-Hall of India Private Limited, New Delhi-110 001, India. 2002.

Copyright (C) 2019 by the authors. This is an open access article distributed under the Creative Commons Attribution License which permits unrestricted use, distribution, and reproduction in any medium, provided the original work is properly cited (CC BY 4.0).

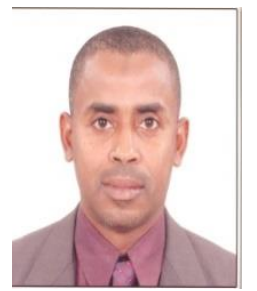

Mohd Elmuntasir Ebrahim Ahmed was born in Khartoum, Sudan and received the B.Sc. (honors) in civil engineering from the University of Khartoum, Khartoum, Sudan in 1992, the M.Ss. in civil engineering (environmental engineering) from Bradley University, Peoria, IL, USA in 1996, and the $\mathrm{Ph} . \mathrm{D}$. in environmental engineering from Illinois Institute of Technology (IIT), Chicago, IL, USA in 2000. Currently, he is a research scientist at the Wastewater Treatment and Reclamation (WTRT) Program at Kuwait Institute for Scientific Research (KISR) in Kuwait.

His experience include: International staff with UN, Regional staff the Nile Transboundary Environmental Action Program, Associate Professor of at the University of Khartoum, Environmental Engineering Consultant with the University of Khartoum Consultancy Corporation, and Graduate Research Assistant at Illinois Institute of Technology. Research areas include: Low energy ion-exchange membrane processes, Adsorption processes, Hybrid biological processes for oil produced water treatment, Decision theory application for wastewater treatment plant operation, and environmental assessment.

Dr Ahmed is a fellow of the Sudanese Engineering Society. He was awarded Who's Who Among American Colleges and Universities (1997) and won many research grants. He has over 30 publications in international scientific journals and conferences. 